\title{
Nurse educators in Australia: High job satisfaction despite role ambiguity
}

\author{
Jan Maree Sayers ${ }^{* 1}$, Yenna Salamonson ${ }^{1}$, Michelle DiGiacomo ${ }^{2}$, Patricia Davidson ${ }^{3}$ \\ ${ }^{1}$ School of Nursing and Midwifery, University of Western Sydney, Sydney, Australia \\ ${ }^{2}$ University of Technology, Sydney, Australia \\ ${ }^{3}$ School of Nursing, John Hopkins University, Baltimore, United States
}

Received: December 8, 2014

Accepted: January 12, 2015 Online Published: January 21, 2015

DOI: $10.5430 /$ jnep.v5n4p41

URL: http://dx.doi.org/10.5430/jnep.v5n4p41

\begin{abstract}
Purpose: The purpose of this study was to describe the nurse educator role in Australian hospitals, including their practice and performance standards.

Methods: A cross-sectional, online survey of nurse educators employed in acute care hospitals in Australia was administered over a three-month period. The survey comprised established and researcher-developed scales, and a single open-ended question. Quantitative data was analysed using descriptive statistics. Qualitative data was analysed using a general inductive approach.

Results: Nurse educators who were more likely to fulfil nurse educator competency practice domains had master's degrees in education, defined professional development needs, and met regularly with their managers. These educators also had higher levels of job satisfaction. Participants identified that role ambiguity and role confusion adversely impacted nurse educator role expectations, responsibilities, and job satisfaction. Despite this, the majority of educators intended to stay in their role for the foreseeable future.

Conclusions: Role ambiguity influenced professional identity and job satisfaction, highlighting the need for clarification of nurse educator roles. These findings suggest the need for review of the nurse educator role and incorporation of professional and educational requirements and practice competencies. Ongoing role monitoring is recommended to identify the effects of role change.
\end{abstract}

Key Words: Job satisfaction, Role, Role ambiguity, Nurse educator, Competencies

\section{Introduction}

Nursing regulatory and professional bodies have determined the standards of education and professional practice necessary for nurses to qualify and provide optimal nursing care. ${ }^{[1]}$ The demands of complex care highlight the practiceeducation gap as nursing education endeavours to keep up with rapid advances in practice and technology. ${ }^{[1]}$ Nurse education in clinical practice is widely acknowledged as an imperative because of the opportunities it affords students and graduate nurses to link theory to practice and continually develop competence and expertise. ${ }^{[1-4]}$ These factors highlight the importance of education in the clinical practice setting - not merely for undergraduate students but for nurses as lifelong learners. ${ }^{[1,5]}$ Varying roles and scope of practice within the nursing workforce further influence the demand for effective clinical education supporting knowledge and skill development. ${ }^{[6,7]}$ Multiple studies have ex-

\footnotetext{
* Correspondence: Jan Maree Sayers; Email: j.sayers@uws.edu.au; Address: School of Nursing and Midwifery, University of Western Sydney, Sydney, Australia.
}

Published by Sciedu Press 
plored the role of the nurse educator or nurse academic in universities. ${ }^{\left[{ }^{8-10]}\right.}$ However, the role of the nurse educator primarily employed in hospitals and responsible for providing education to students and graduate nurses, has been minimally explored in the literature. ${ }^{[4]}$ To address this paucity, we conducted a study of nurse educators working in acute care hospitals in Australia. This paper reports the study findings.

\section{Background}

The nurse educator role has changed over time. Nurse educators initially, assumed overall responsibility for student nurse education in hospital based training courses. ${ }^{[4,11]}$ Within this role, they were also responsible for conducting continuing education and professional development courses and monitoring standards of practice. ${ }^{[11]}$ The nurse educator role in hospitals became less well defined following the transfer of nurse education to universities and colleges. ${ }^{[4,10,11]}$ In some countries, the role may comprise a shared appointment between a hospital and university where the focus is on facilitating students or may be primarily hospital based within a ward, specialty, or across a group of hospitals. ${ }^{[2,4]}$ Differing titles have been applied to various nurse educator roles. In the United Kingdom, the 'practice educator' role focuses on teaching and assessing students and graduates in clinical practice and supporting staff in clinical practice. ${ }^{[12]}$ In the United States of America (USA) and Australia, the "clinical nurse educator" works with both students and graduate staff in hospitals. ${ }^{[4]}$ In Australia, a range of other titles also apply to nurses involved in education. These include nurse academics, nurse educators, and clinical facilitators. ${ }^{[4]}$

In the current study, we defined a nurse educator as a registered nurse and professional expert with primary responsibility for providing education to undergraduate and postgraduate nursing students and graduate nurses within a hospital setting. ${ }^{[13]}$ In this context, nurse educators in hospitals may also assume responsibility for providing clinical education and professional development courses, as opposed to nurse educators working in universities and colleges who may have responsibility for student education, research, and scholarship. ${ }^{[4]}$ This paper reports findings from a study of nurse educators working in Australian hospitals, and how they describe and perceive their role and scope of practice within their practice setting. ${ }^{[13]}$

\section{Method}

\subsection{Aims}

The aim of the study was to describe the nurse educator role in acute care hospitals, including their practice and performance standards.

\subsection{Design}

A cross sectional survey design was used.

\subsection{Participants}

The study used a convenience sample of nurse educators working in acute care hospitals in Australia. The total number of nurse educators in Australia is unknown because no register of this position currently exists. Participants were targeted through nursing organisations, nursing leaders and networks, and study advertisements in professional and academic nursing journals and websites. Nurse educators registered their intention to participate via email response to the researcher. Following these initial recruitment notices, snowball sampling was enacted whereby these networks disseminated the survey link.

\subsection{Survey tool}

Item generation was informed by a literature review, position descriptions, and consultation with an expert panel. The researcher logically grouped survey items to ensure the research questions could be answered. These groupings covered questions pertaining to participant demographics, educational characteristics, reporting and performance management, activities and competencies, role support, retention, and the professional practice environment. Two researcherdeveloped scales the (Activities and Competencies of Nurse Educator (ACONE) and the Importance of Support for the Nurse Educator Role (ISNER) scales) and two previously validated scales Nurses' Retention Index (NRI) (Cronbach alpha 0.96) ${ }^{[14]}$ and Professional Practice Environment (PPE) (Cronbach alpha 0.93 $)^{[15]}$ were included in the survey. Descriptions of survey components are summarised in Table 1. In the final section of the survey, a single open-ended item asked: "If there are any comments you would like to share regarding the nurse educator role, please feel free to make the comments in the section below." This item enabled respondents to provide a descriptive account of the scope of their work and work environment. This approach mitigated the limitations of quantitative items by allowing for contextual nuances to be stated.

The survey was initially piloted by a group of academics, nurse educators working in acute care hospitals, and representatives from professional bodies. Following two survey iterations, an online pilot was conducted with another group of expert nurses $(n=9)$ who assessed the content validity of the scales. This group identified further changes enhancing item clarity, layout, and additional content required.

\subsection{Data collection}

The survey was administered using Survey Monkeyß a commercial web-based platform. Data collection occurred between October 2009 and January 2010. To circumvent issues related to limited internet access in rural and remote 
areas and to maximise participation, hardcopies of the questionnaire were posted to acute care hospitals Australia-wide $(\mathrm{n}=356)$. Participants who completed hardcopies posted or faxed these back to the researcher and these data were entered into the online survey by a research assistant. Consent to participate was given prior to completing the survey. The study was approved by the relevant University's Human Research Ethics Committee.

Table 1: Survey Components

\begin{tabular}{|c|c|}
\hline Survey Component & Item Description \\
\hline $\begin{array}{l}\text { Socio-demographic \& } \\
\text { Educational Characteristics }\end{array}$ & $\begin{array}{l}13 \text { items: sex, age, Aboriginal or Torres Strait Islander status, position title, time in position, employment } \\
\text { status, contractual status, location, facility classification, specialty qualifications, perceptions about } \\
\text { qualifications required, and current study. }\end{array}$ \\
\hline Reporting and Performance & $\begin{array}{l}17 \text { items: job description; report to; duty statement reviewed recently; frequency of meetings with } \\
\text { manager; appraisal; identification of professional development and learning needs; performance } \\
\text { development plan; role specific clinical or performance indicators. }\end{array}$ \\
\hline \multirow[t]{2}{*}{$\begin{array}{l}\text { Activities and Competencies } \\
\text { of Nurse Educators (ACONE) }\end{array}$} & $\begin{array}{l}\text { Activities -13 items: An 11-point response format ( } 0 \text { denoting nil time spent and } 10 \text { denoting } 91-100 \\
\text { percent of time spent each week) seeking the average percentage of time spent each week undertaking: } \\
\text { specific activities - patient care, teaching, competency assessment, curriculum development, program } \\
\text { planning and co-ordination, role relief and committee participation; and providing education to specified } \\
\text { groups: nurses, non-health professional staff, nursing students, volunteers and community members, and } \\
\text { other healthcare professionals. }\end{array}$ \\
\hline & $\begin{array}{l}\text { Competencies -36-items. Respondents reported, on an } 11 \text { - point Likert scale, the extent to which they } \\
\text { undertook various competencies, } 0 \text { denoting never and } 10 \text { denoting always. }\end{array}$ \\
\hline Self-appraisal of Performance & $\begin{array}{l}1 \text { item: a Likert scale from } 0 \text { to } 10 \text { with } 0 \text { depicting perception of poor performance and } 10 \text { depicting } \\
\text { excellent performance. }\end{array}$ \\
\hline $\begin{array}{l}\text { Workplace Issues - Importance } \\
\text { of Support for Nurse } \\
\text { Educator's role (ISNER) scale }\end{array}$ & $\begin{array}{l}8 \text { items: an 11-point Likert scale from } 0 \text { - } 10 \text { with } 0 \text { denoting items to be of very low importance and } 10 \\
\text { denoting items of high importance. Items: the level of importance of increasing the focus on } \\
\text { inter-professional teaching and learning, developing strategies to promote an advanced practice role, } \\
\text { promoting initiatives to foster team work and multidisciplinary care, addressing factors relating to skill } \\
\text { mix diversification, endorsing the interface between health care settings and educational providers, } \\
\text { increasing the focus on research and scholarship, linking nurse education activities to patient outcomes, } \\
\text { and advancing the role within the nursing profession using. }\end{array}$ \\
\hline Role Overlap and Ambiguity & $\begin{array}{l}1 \text { item: respondents rated their perception of whether or not there was blurring and overlap of nurse } \\
\text { educator activities with other nursing roles, using a 10-point Likert scale. Zero depicted no role overlap } \\
\text { and role ambiguity while ten depicted very much overlap and ambiguity. }\end{array}$ \\
\hline $\begin{array}{l}\text { Career Intentions - Nurses' } \\
\text { Retention Index (NRI) }{ }^{[14]}\end{array}$ & $\begin{array}{l}\text { 6-items: measured nurses' intention to stay in the workforce using an 8-point Likert scale. Item } 3 \text { (As soon } \\
\text { as it is convenient for me, I plan to leave the nursing profession) and item } 6 \text { (I would like to find other } \\
\text { employment by leaving nursing) were constructed to measure the inverse of the construct and were } \\
\text { reversed during analysis: Cronbach alpha }>.90 \text { for the original study. }{ }^{[14]}\end{array}$ \\
\hline $\begin{array}{l}\text { Professional Practice } \\
\text { Environment (PPE) }\end{array}$ & $\begin{array}{l}38 \text { items: using a Likert scale from 1-4 rating agreement with the items: measuring nurses' work } \\
\text { satisfaction within their practice environment across eight domains - handling disagreement and conflict, } \\
\text { internal work motivation, control over practice, leadership and autonomy in clinical practice, staff } \\
\text { relationships with physicians, teamwork, cultural sensitivity, and communication about patients, } \\
\text { workplace conflict, personal satisfaction, and continuity of care. Cronbach alpha >.93 for the original PPE } \\
\text { study. }{ }^{[15]}\end{array}$ \\
\hline
\end{tabular}

\subsection{Data analysis}

Data were analysed using SPSS for Windows Version 18. Descriptive statistics (frequencies, mean, standard deviation (SD), and range) were calculated. Internal consistency was evaluated using the Cronbach alpha statistic. Factor analysis was used to assess the underlying dimensions of scales ${ }^{[16]}$ and the identification of any relationships between variables and item grouping. ${ }^{[1]}$ The Importance of Support for the Nurse Educator Role (ISNER) scale was subjected to the Kaiser-Meyer-Olkin (KMO) and Bartlett's test of sphericity

Published by Sciedu Press prior to principal component analysis. ${ }^{[17]}$

Qualitative responses to the open-ended item were imported into an Excel spread sheet. Using an inductive approach, two researchers independently and repeatedly read each line of the data and added a 'code' describing its content. ${ }^{[18]}$ Data codes were grouped into categories and then recoded into themes and subthemes. Throughout this process the researchers looked for relationships and irregularities within the data. Content that did not fit the initial categories were classified as additional categories. The survey questions 
also guided the analysis and final coding. Data coding facilitated classification of the data for subsequent comparison with other elements of the data set. ${ }^{[18]}$ Triangulation of both data sets followed discrete reporting of individual data sets. ${ }^{[19]}$ Triangulation enabled a fuller picture of the nurse educator role to emerge as well as confirming the data and data completeness.

\section{Results}

The survey completion rate was $95 \%(n=425)$. Of these, 46 were hardcopy questionnaires returned via facsimile or post. The response rate to the single open-ended item was $38.3 \%(n=165)$. Findings from qualitative and quantitative data have been integrated in the presentation of results.

\subsection{Participant characteristics}

A profile of socio-demographic and educational characteristics of participants and reporting and performance data are summarised in Table 2. Performance management data are summarised in Table 3. Nurse educators reported high levels of self-appraised performance (see Table 3 ).

Table 2: Characteristics of participants $(n=425)$

\begin{tabular}{|c|c|c|}
\hline Characteristics & $n$ & $\%$ \\
\hline Sex (Male/Female) & $51 / 374$ & $12 / 88$ \\
\hline \multicolumn{3}{|l|}{ Age group (years) } \\
\hline$<30$ & 36 & 8.5 \\
\hline 31 to 35 & 46 & 10.8 \\
\hline 36 to 40 & 81 & 19.1 \\
\hline 41 to 45 & 70 & 16.5 \\
\hline 46 to 50 & 91 & 21.4 \\
\hline 51 to 55 & 64 & 15.1 \\
\hline 56 to 60 & 27 & 6.4 \\
\hline$>60$ & 10 & 2.4 \\
\hline \multicolumn{3}{|l|}{ Position title } \\
\hline Clinical Nurse Educator & 171 & 40.2 \\
\hline Clinical Development Nurse & 6 & 1.4 \\
\hline Clinical Coordinator & 6 & 1.4 \\
\hline Staff Development Educator & 24 & 5.6 \\
\hline Nurse Educator & 160 & 37.6 \\
\hline Clinical Facilitator & 9 & 2.1 \\
\hline Nurse Education Coordinator/Manager & 37 & 8.7 \\
\hline Clinical Nurse Consultant & 9 & 2.1 \\
\hline Other & 3 & 0.7 \\
\hline \multicolumn{3}{|l|}{ Employment status } \\
\hline Full time & 272 & 64.0 \\
\hline Part time & 145 & 34.1 \\
\hline Other & 8 & 1.9 \\
\hline \multicolumn{3}{|l|}{ Educational Qualification } \\
\hline Master's degree or above & 93 & 21.9 \\
\hline
\end{tabular}

Table 3: Reporting and performance management

\begin{tabular}{lll}
\hline Management structure & $\mathbf{n}$ & $\mathbf{\%}$ \\
\hline Directly reporting to the following management position & & 40.5 \\
Nursing - Clinical & 172 & 34 \\
Nursing - Education & 146 & 3.5 \\
Professional Development & 15 & 1.4 \\
Non-nursing - Clinical & 6 & 2.6 \\
Non-nursing - Education & 11 & 17.7 \\
Other & 75 & 94.8 \\
Performance Management & & 41.6 \\
Job description & 399 & 72.9 \\
Duty statement reviewed within last 12 months & 177 & 69.6 \\
Regular meeting with line manager & 310 & 61.9 \\
Appraisal and performance review within last 12 months & 274 & 263 \\
Professional development and learning needs identified & & \\
\hline
\end{tabular}




\section{Role criteria and education qualifications}

Within the free text responses, participants described role criteria and educational qualifications perceived necessary for their position as nurse educators. Respondents indicated that identifying these facets were necessary for clarification of their role and responsibilities. Explication of these criteria also served to perpetuate a shared understanding within the nursing profession regarding the foundational knowledge necessary to expand the skills and expertise required of nurse educators.

Respondents reported that nurse educator roles and responsibilities varied across different settings. These perceptions were illustrated by comments from an educator working in a rural area highlighting the complexity of the role in comparison to the role in a metropolitan hospital, where the educator may have responsibility for a single unit only.

“... The regional Nurse Educator is responsible for many clinical areas, with diverse clinical requirements. I cover from a generalist medical ward to the specialist units over all approx. 192 staff. I also have program accountabilities such as undergraduate placements training for supervision, competency assessment and development ... for the entire health service approx. 500 staff."

Participants identified that it was important for nurse educators to have specialised education qualifications, and associated knowledge and skills to teach.

"The concept that 'every nurse is a teacher' serves to obfuscate the real and pressing need to have NEs educationally prepared as educators. A generic Master's degree and perhaps a Cert ... in [Training and Assessment] is not enough to equip a nurse to meet the challenges of the NE role in clinical practice."

As seen in this excerpt, expectations regarding knowledge and expertise were voiced. An educator from a major city hospital identified the need for the nurse educator to be an expert clinician applying advanced clinical knowledge and expertise to facilitate individual development of clinical practice.

“... The critical skills for nurse educators to possess revolve around the educator's clinical acumen and the ability to analyse and constructively support the development of other's practice..."

\subsection{Role ambiguity and overlap}

Role ambiguity occurs when role definition and performance expectations are unclear. ${ }^{[20]}$ Role overlap refers to situations where the designated responsibilities of a particular role are also found in other roles. ${ }^{[20]}$ All respondents indicated some degree of role-blurring and overlap of their activities with other nursing roles as measured by this singleitem question (Mean: 6.2, SD: 2.5, Range: 0-10). Over half of the respondents indicated the presence of role blurring and overlap of activities with other nursing roles (see Table 4).

Table 4: Activities and competencies, self-appraisal of performance, role blurring, career intentions and professional practice environment components

\begin{tabular}{lcc}
\hline Survey Component & Mean & SD \\
\hline $\begin{array}{l}\text { Activities and Competencies of Nurse Educators (ACONE) scale } \\
\text { (Possible range: } 0 \text { to 360) }\end{array}$ & 245.6 \\
$\begin{array}{l}\text { Career Intentions -Nurse Retention Index (NRI) } \\
\text { (Possible range: } 6 \text { to 48) }\end{array}$ & 40.4 \\
$\begin{array}{l}\text { Professional Practice Environment (PPE) scale } \\
\text { (Possible range: } 38 \text { to 152) }\end{array}$ & 106.6 \\
Workplace issues - Importance of support for nurse educator's role (ISNER) scale (Possible range: 0 to 80$)$ & 65.3 \\
Self-appraisal of performance (Possible range: 0 to 10) & 7.3 \\
Role-blurring and ambiguity (Range: 0 to 10) & 6.3 & 9.5 \\
\hline
\end{tabular}

Note. SD = Standard Deviation

\subsection{Job satisfaction}

The four standardised scales used in the survey were related to professional identity and job satisfaction. These were the ACONE, ISNER, NRI and PPE scales, as described in the following sections:

\subsubsection{Activities and Competencies of Nurse Educators (ACONE) scale}

Nurse educators reported that they engaged in a wide range of duties and tasks in their practice each week (see Figure 1). Six competency domains were identified from the 
36-item ACONE scale, reflecting the scope of practice of nurse educators across Australia. These are: i) education program development; ii) teaching and mentoring; iii) educational \& clinical leadership; iv) professional practice im- provement; v) research and scholarship; and vi) education management. Nurse educators reported high levels of selfassessment of competency against these domains (see Table 4). Cronbach's alpha of the overall 36 items was 0.94 .

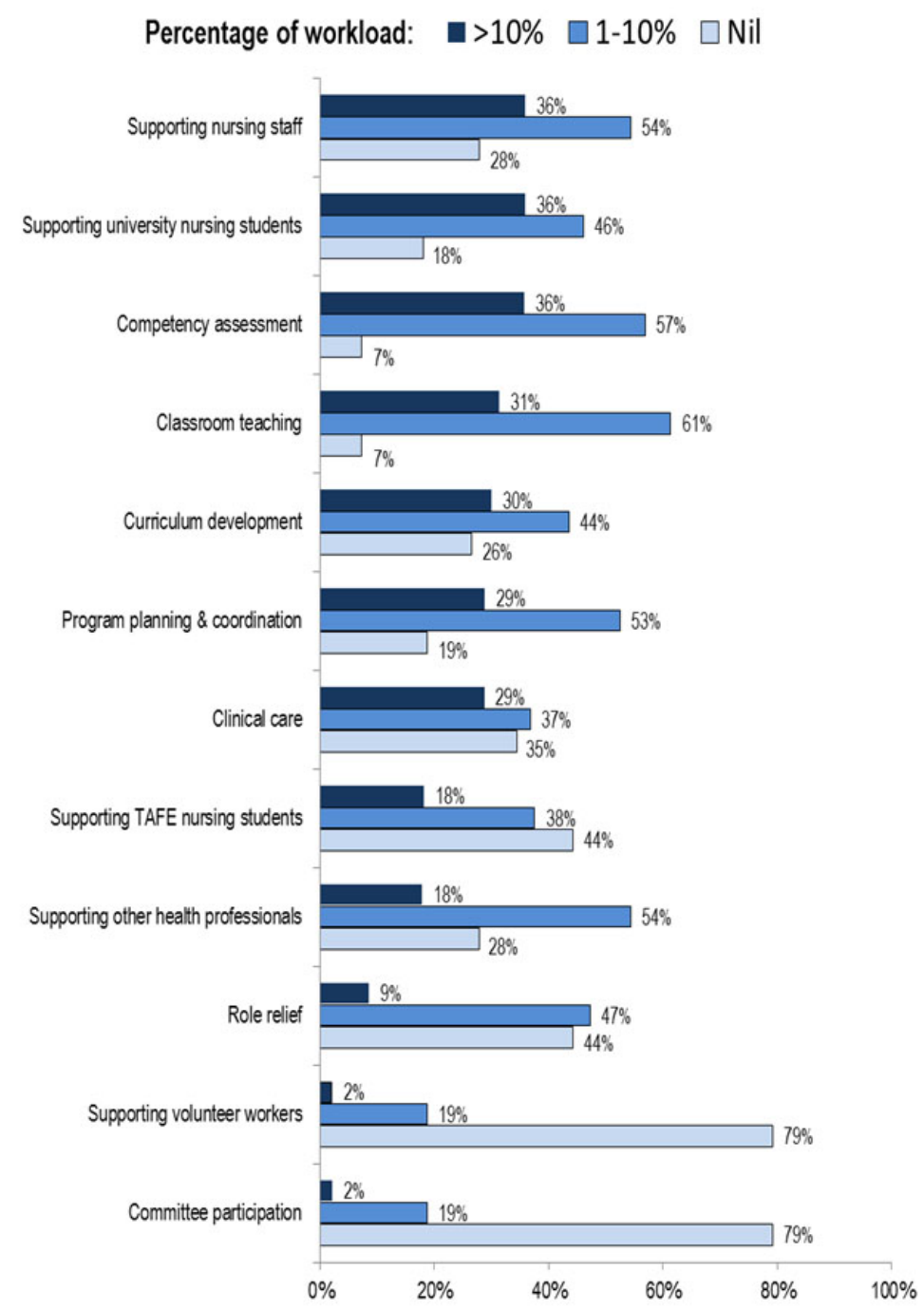

Figure 1: Nurse Educator Activities

\subsubsection{Importance of Support for Nurse Educator (IS- NER) scale}

Principal components analysis revealed a single component solution labelled "Importance of Support for the Nurse Educator Role". Cronbach's alpha for the 8-item scale was 0.81 . The distribution of scores was skewed (Mean: 65.3, SD: 9.5, Range: 0-80), indicating that there was strong consensus regarding the importance of support for the nurse educator role (see Table 4).

\subsubsection{Career intentions - Nurses' Retention Index (NRI)}

Factor analysis for the Nurses' Retention Index ${ }^{[14]}$ yielded a one-component solution. Cronbach's alpha was 0.91, com- parable with 0.90 value reported by Cowin. ${ }^{[14]}$ Survey respondents indicated a strong intention to stay in their current positions (Mean: 40.4, SD: 7.9, Range: 6-48) (see Table 4).

\subsubsection{Professional Practice Environment (PPE)}

Erickson's eight dimensions were extracted, with component loadings ranging between 0.35 and $0.85 .{ }^{[15]}$ However, cross-loadings were also detected in several items, probably due to the diversity of role requirements in various geographical settings. Cronbach's alpha was 0.92 (see Table 4), similar to the 0.93 reported by Erickson. ${ }^{[15]}$ Respondents reported high levels of satisfaction with their practice environment with $78 \%$ reporting a score above the 95 midpoint score. 


\subsection{The impact of role ambiguity on job dissatis- faction}

Role ambiguity refers to unclear role parameters, ${ }^{[20]}$ whereas role overload occurs when a person has excessive responsibilities and is unable to complete their work. Role erosion occurs where a person perceives they have fewer responsibilities and are underutilized. ${ }^{[21]}$ These factors, either individually or collectively, contribute to role stress where there a mismatch between role expectations and performance outcomes. ${ }^{[22]}$

\subsubsection{Role ambiguity, erosion, and blurring tax nurse ed- ucator resources}

Role blurring and misconceptions occurred when role expectations and responsibilities were not clearly understood by staff, particularly in hospitals where two educator roles exist: the nurse educator (NE) and the clinical nurse educator $(\mathrm{CNE})$

One experienced educator highlighted the "misconceptions" held by other nursing staff about her role:

"I work in a unit where the staff has no idea what the difference is between a CNE and a NE.... For years they only had a NE who worked clinical when needed (regularly) and had no recognized post grad qualifications. Now the staff don't think you do any work unless you work clinically which isn't in my job description..."

This educator expressed feelings of frustration and being demoralised as her efforts to work within her role boundaries were not sanctioned by her nursing colleagues. This mismatch of expectations potentially impacts personal resilience and job satisfaction. The importance of nurse educators profiling their role was also highlighted in these comments. These beliefs reinforce the responsibility of management in specifying role responsibilities and boundaries as well as providing role support and effective utilization of the nurse educators within hospitals. These strategies support role identity and are important to avoid role overload and erosion.

\subsubsection{Organisational culture as devaluing the $\mathrm{NE}$ role}

Pervading organizational attitudes to education may promote limited understanding of the need for an educated and competent workforce to address the requirements associated with higher patient acuity.

The following remarks depict the lack of recognition of the value and impact of the $\mathrm{NE}$ role, within an organisation: ${ }^{[23]}$

"I have worked as an educator previously within the public sector and was given a lot more opportunity to function highly in the role. The public system seems to rely more on the non-clinical staff to back fill sick leave and relieve for meal breaks. This is extremely frustrating when I've studied very hard to get where I am. The staff don't understand the nonclinical skills that nurse educators have. The point, I feel, is that you don't have to be involved in direct patient care to help patients."

The nurse educator had different expectations of her role when she moved from a private hospital to a public hospital. On the basis of this experience she anticipated her role in the public sector would allow continued demonstration of her capabilities and expertise. However, she expressed her frustration and feeling of isolation in response to the limitations imposed by her new role and arising from the staff's lack of understanding and organisational structures.

Another important factor is workforce diversity associated with variable skill sets and levels of educational attainment, as highlighted by the following nurse educator:

"Support not given to education - the culture is not focussed towards continuing education, despite continually changing evidence ... Increasing patient acuity and decreasing staff skills/years of experience equate to a greater need for clinical education, but where is the initiative to support it?"

This excerpt depicts hospital culture as inherently influencing staff culture and devaluing of the NE role. Feelings were expressed of not being valued, being misunderstood, and contributions to patient care overlooked or unsupported by management. Another educator from a city centre perceived her expertise and credibility was undervalued.

"I feel the value of the role in some cases is seriously underestimated by many of the "powers that be' ... Clinicians undervalue the knowledge and clinical skills of educators and frequently quip that 'they are just educators'. Educators are obviously not respected by the majority for whatever reason until such time as they feel that there is a role that can be added to their already overwhelming function."

The effects of devaluing were further exemplified when a ward-based nurse educator was called upon to assume a patient load providing direct clinical care - casting aside her primary function as an educator - when staffing deficits arose.

"Educator time within our organisation is not protected so when staffing numbers are low ed- 
ucators are frequently pulled from their educational roles to provide direct clinical care."

This educator expressed her concern, frustration, and feelings that it was an accepted practice for nurse educators to be used to replace clinical staff and that she had no control in this practice.

\subsection{Summary of findings}

Comparative analysis with data from the ACONE scale and the single item text responses revealed that those who were more likely to make comments indicating presence of role blurring and ambiguity were those who spent less of their work time: (i) supporting nurses and (ii) supporting other health professionals. The findings from both qualitative and quantitative data highlighted factors influencing nurse educator practice. These factors are: educational qualifications; competency, and reporting and performance management; and role ambiguity, blurring, and devaluing. These were important factors influencing role enactment and job satisfaction across both data sets. Participants considered that their peers, managers, or organisations were also unclear about these factors. For some educators, not having clear boundaries about their role caused confusion within themselves and others and in turn, created feelings of job dissatisfaction.

\section{Discussion}

Our results contribute to the international literature by providing an understanding of the role and scope of practice of nurse educators in Australian hospitals. The survey participants were mostly female (88\%), which is slightly lower than the percentage of female nurses in Australia (90.6\%). Interestingly, this sample had a higher proportion of males (12\%) compared with the number of males nurses in Australia overall $(9.6 \%){ }^{[24]}$ This finding may indicate that males may find nurse education an attractive career pathway.

Nurse educators in this study were involved in the full spectrum of education functions from providing one-to-one education at the point of care, to formal education program development, implementation, and evaluation. Nurse educators primarily provided education to nursing students and other registered nurses, healthcare professionals, administrative staff, and volunteers.

As highlighted in open-ended responses, views of the nurse educator role and responsibilities varied. Defining nursing roles provides clarity for nurses, health professionals and patients about the scope of a particular role and performance expectations. ${ }^{[25-27]}$ Role definitions also provide information about expected and desired attributes such as educational qualifications, competencies and responsibilities, and reporting lines. ${ }^{[22]}$ Establishing consensus about role definitions and responsibilities is necessary to optimise role enactment, maintain job satisfaction, ${ }^{[28]}$ attract nurses to the speciality and inform peers and other professionals understanding of role expectations. ${ }^{[4]}$

\subsection{Educational preparation}

In Australia, registered nurses are required to have a Bachelor's degree although some register at a master's level. Competency standards for the registered nurse defined by the Australian Nursing \& Midwifery Council ${ }^{[27]}$ guide nurse educator practice whilst specialty nurses (e.g. intensive care nurses) require advanced knowledge, skills and expertise to perform within their practice specialty. ${ }^{[26,29]}$ Survey respondents stated their perception that educators need to be both clinically competent and have qualifications in education. We also argue that whilst the nurse educator needs to be clinically competent, this expertise is insufficient for professional practice within the nurse educator specialty. Few nurse educators in our sample had an education qualification at the master's level. In light of this, we argue that a reasonable expectation would be that nurse educators require specialty education at a master's level. Masters programs enable the spiralling development of theoretical knowledge, critical appraisal and synthesis and translation of research to practice. These attributes would provide nurse educators with foundational skills to develop their expertise and drive the ongoing development of nurse education practice. Whilst education requirements for nurse educators are unclear, this may adversely influence efforts to foster role identity and credibility. ${ }^{[4]}$

\subsection{Feedback on performance}

Nurse educators highly value the importance of receiving feedback to improve role effectiveness. Furthermore, those who are not supported through regular performance feedback may disengage from their work and workplace as highlighted in comments made about role devaluing. Staff who have career opportunities identified and professional development supported, perceive that their contribution to their workplace is valued. Where this does not occur, as identified in comments from participants, role conflict may arise along with perceptions of the role being devalued. This may be mitigated through management support and performance review providing opportunities to receive feedback on performance and to identify and negotiate future career and performance goals. ${ }^{[27,30]}$ Performance review will also allow comparisons between self-assessment of performance and the perceptions of other stakeholders. The valuable contribution of nurse educators to continuing professional education and their influence on policy and patient outcomes may be validated through performance review inclusive of these measures. Adopting strategies in this discussion will provide nurse educators, their managers and other clinicians 
with clear direction regarding their role and performance expectations.

\subsection{High job satisfaction despite role ambiguity and role blurring}

Nurse educators indicated a high level of self-appraisal of their performance and the majority intended to stay in their current role in the foreseeable future. However, concerns expressed regarding role blurring and ambiguity persist. ${ }^{[11]}$ The majority of participants indicated satisfaction with their practice environment overall, however, this was overshadowed by respondents perceptions of role blurring and ambiguity. Role blurring and ambiguity may negatively influence nurse educator performance and job satisfaction. ${ }^{[25]}$ Left unchecked, role ambiguity may diminish role identity and role conflict may arise. ${ }^{[4]}$ These issues may have been compounded by the restructuring of nursing roles in recent years and limited acknowledgement of the effect of these changes on the nurse educator role. ${ }^{[4]}$

Role blurring and ambiguity was reported among nurse educators who spent less time supporting nurses and less time supporting other health professionals. Regular redeployment of nurse educators to provide patient care when staffing deficits occur generates role confusion and potentially a loss of job satisfaction for nurse educators. Redeployment as a consequence of inadequate staffing and perceptions of not being supported by management are predictors of work related stress and may lead to staff burnout. ${ }^{[31]}$ This may also occur when nurse educators were 'wearing many hats' with dual responsibilities such as education and infection control within a hospital. These examples highlight the competing priorities nurse educators encounter in their work and how these may make them feel frustrated or concerned about their ability to meet their own expectations as well as those of their peers and managers. Whilst higher patient acuity and staff mix availability increasingly require a degree of flexibility in all roles, ${ }^{[25]}$ it is equally important that nurse educators and managers work collaboratively to ensure that nurse educators are able to work optimally and continue to be satisfied in their job. Promoting positive practice environments, where staff are supported by management, contributes to job satisfaction, and retention. ${ }^{[31]}$ Given the complexities of the acute care environment, nurse educators are pivotal in supporting nursing staff to provide competent quality care. Links between burnout of nursing staff, quality of care and job satisfaction in acute care hospitals are widely acknowledged in the nursing literature. ${ }^{[31-33]}$ Nurse educators may be burdened by the degree of emotional support that is required of them when supporting staff as well as experiencing some degree of stress themselves. Peer and management support to mitigate these effects thereby promoting positive practice environments and enhancing job satisfaction is essential. Nurse educators also need to develop self-care skills and resilience to recognise and manage burnout in their lives to maintain high levels of job satisfaction. ${ }^{[31]}$

The increasing complexity of health care environments, coupled with changing nursing workforce roles, may also influence a loss of group identity for nurse educators. Although individual nurse educators may be cognisant of the perceived threat to their identity, they often neglect to recognise the importance of articulating their practice and professional and organisational contribution to promote their specialty role and practice. ${ }^{[2,4,11]}$ This was evident in their selfassessment of competency where there was limited evidence of their contribution to research and scholarship. Nurse educators could readily address this through conference presentations, writing for publication and active participation in professional organisations. Another strategy would be to engage in communities of practice. ${ }^{[35]}$

\subsection{Moving forward}

Nurse educators are leaders and change agents within the nursing profession. Nurse educators demonstrate leadership by being effective role models for students and graduate nurses. Another leadership attribute is their capacity as change agents driving the development and implementation of evidence in clinical practice. ${ }^{[1,11]}$ Addressing the needs of diversely skilled students and graduates requires educators with expert knowledge to guide and support individual staff as they transition from novice to expert. This is contingent upon healthcare infrastructure to recruit, support and sustain competent nurse educators. A career pathway may enhance role development and career advancement. ${ }^{[36]}$ Continued development of the nursing profession and its ability to address society's healthcare needs is implicit upon the nurse educator role. ${ }^{[1]}$ If teaching and learning is valued as core business in clinical practice environments, then the contribution of nurse educators through role modelling, guiding the development and implementation of evidence, and enabling learning and skill acquisition is invaluable. The recent move to national nurse registration and the associated requirement for mandated continuing professional education in Australia may also impact on the provision of nurse education in clinical practice environments. ${ }^{[36]}$ Consequently, the role of the educator in providing these programs needs to be addressed.

\subsection{Implications for policy, practice, and research}

Nurse educators both in Australia and internationally will continue to address education and practice requirements, and contribute to the development of a competent and capable workforce. ${ }^{[1,5]}$ The findings from this study highlight the need for regulatory bodies, nurse educators, hospitals and professional associations to work collaboratively to review the nurse educator role and integrate professional and educational requirements and practice competencies in role development particularly in light of concerns raised about 
role blurring and ambiguity. This is also important to ensure effective utilisation of nurse educators within the nursing workforce as well as promoting the role as a career option. Ongoing role monitoring is recommended to identify the effects of role change on job satisfaction and role effectiveness. Further research to determine the impact of nurse educator practice on patient outcomes is important to demonstrate the influence of the role on advancing practice and patient safety. ${ }^{[13]}$

\subsection{Limitations and strengths}

Among the limitations in this study is sample selection. The lack of a defined sampling frame precluded random sampling. To mitigate this, an exhaustive list of educators were contacted and offered different methods of completing the survey. Another limitation of the study is that the viewpoints of managers regarding the role were not solicited as part of the study. Comparing perspectives of both management and nurse educators would further inform opportunities for role clarification and identify the relationships between role ambiguity, role stress and organisational climate. Also, the ACONE competencies require further validation in practice. Although these data pertain to nurse educators in Australia, it is likely that these data have salience and relevance to an international audience of nurse educators working in hospitals and within the broader nursing profession where nursing roles are reviewed and clarified.

\section{Conclusion}

Despite the high job satisfaction level, this study also identified role ambiguity, blurring and overlap between the nurse educator role and other nursing roles with responsibility for education in Australian hospitals. Role conflict influences nurse educator job satisfaction, effectiveness and professional identity. Role clarity and validation of performance is crucial to role enactment, effectiveness, and influencing teaching and learning in clinical practice. Nurse educator competencies are influential in role development, recruitment and career progression. Further role monitoring may ascertain the continued effects of role change, service provision, and the impact of the nurse educator role on patient outcomes.

\section{Conflicts of Interest Disclosure}

The authors declare that there is no conflict of interest statement.

\section{References}

[1] Benner P, Sutphen M, Leonard V, Day L, Schuman, LS. Educating nurses: A Call for Radical Transfromation. San Francisco: JosseyBass 2010.

[2] Adelamn-Mullally T, Mulder CK, McCarter-Spalding DE, Heghler DA, Gaberson KB, Hanner, MB, Young, PK. The clinical nurse educator as leader. Nurse Education in Practice. 2013; 13(1): 29 34. PMid: 2285431 http://dx.doi.org/10.1016/j.nepr. 20 12.07 .006

[3] Adeniran RK, Smith-Glasgow ME, Bhattacharya A, Xu Y. Career advancement and professional development in nursing. Nursing Outlook. 2013; 61(6): 437-466. PMid: 22157789 http://dx.doi .org/10.1016/j.outlook. 2013.05.009

[4] Sayers JM, DiGiacomo M, and Davidson PM. The nurse educator role in the acute care setting in Australia: important but poorly described. Australian Journal of Advanced Nursing Nursing. 2011; 28(4): 44-52.

[5] Daly J, Macleod Clark J, Lancaster J, Orchard C, Bednash G. The Global Alliance for Nursing Education and Scholarsip: Delivering a vision for nursing education. International Journal of Nursing Studies. 2008; 45(8): 1115-1117. PMid: 17905255 http://dx.doi.o rg/10.1016/j.ijnurstu.2007.08.002

[6] Conway J, The changing skill mix and scope of practice of health care workers in New South Wales: Implications of education and training reforms for registered nurse practice, performance and education. Contemporary Nurse. 2007; 26(2): 221-224. PMid: 18041973

[7] McHugh MD, ET Lake. Understanding clinical expertise: nurse education, experience and the hospital context. Research in Nursing and Health. 2010; 33(4): 276-287. http://dx.doi.org/10.10 02/nur. 20388
[8] Gui L, Gu S, Barriball KL, While AE, Chen, G. The working lives of nurse teachers in mainland China and the United Kingdom: A questionnaire survey. Nurse Education Today. 2013; 34(5): 730737. PMid: 24021841 http://dx.doi.org/10.1016/j.nedt. 2013.08.010

[9] Duffy R, Nurse to educator? Academic roles and the formation of personal academic identities. Nurse Education Today. 2013; 33(6): 620-624. PMid: 22922027 http://dx.doi.org/10.1016/j.n edt. 2012.07.020

[10] Griscti O, Jacono B, Jacono J.The nurse educator's clinical role. Journal of Advanced Nursing. 2005. 50(1): 84-92. PMid: 15788068 http://dx.doi.org/10.1111/j.1365-2648.2004.03351.x

[11] Conway J, Elwin C. Mistaken, misshapen and mythical images of nurse education: Creating a shared identity for clinical nurse educator practice. Nurse Education in Practice. 2007; 7(3): 87-194. PMid: 17689443 http://dx.doi.org/10.1016/j.nepr.2006.08.00 5

[12] Jowett R, McMullan M. Learning in practice - practice educator role. Nurse Education in Practice. 2007; 7(4): 266-271. PMid: 17689452 http://dx.doi.org/10.1016/j.nepr.2006.08.008

[13] Sayers J.M, The role of the Nurse Educator in acute care hospitals:Australia [dissertation] [Perth]: Curtin University of Technology, 2014.

[14] Cowin L, The effects of nurses job satisfaction on retention. Journal of Nursing Administration. 2002; 32(5): 283-291. PMid:12021569

[15] Erickson JI, Duffy ME, Gibbons MP, Fitzmaurice J, Ditomassi M, Jones D., Development and psychometric evaluation of the professional practice environment (PPE) scale. Journal of Nursing Scholarship. 2004; 36(3): 279-285. PMid: 15495499

[16] Kleinbaum DG, Kupper LL, Muller KE. Applied regression analysis and other multivariable methods. Belmont, California: Duxbury Press, Thompson Higher Education. 2008. 
[17] Tabachnick BG, Fidell LS. Using Multivariate Statistics. 5th ed Boston, MA: Allyn and Bacon. 2007.

[18] Thomas DR, A general inductive approach for analysing qualitative evaluation data. American Journal of Evaluation. 2006; 237(237246). http://dx.doi.org/10.1177/1098214005283748

[19] Creswell JW, Plano Clark VL. Designing and Conducting Mixed Methods Research. Thousand Oaks, California: Sage. 2007.

[20] Schulz J, The impact of role conflict, job ambiguity and organizational climate on the job satisfaction of academic staff in researchintensive universities in the UK. Higher Education Research and Development. 2013; 32(4): 464-478. http://dx.doi.org/10.1080 /07294360.2012.680209

[21] Ahmaday S, Changiz T, Masiello I, Brommels M. Organisational role stress among medical school faculty membes in Iran: dealing with role conflict. BMC Medical Education. 2007; 7(14). PMid: 17535421 http://dx.doi.org/10.1186/1472-6920-7-14

[22] Brookes K, Davidson PM, Daly J, Halcomb, EJ. Role theory: A framework to investigate the community nurse role in contemporary health care systems. Contemporary Nurse. 2007; 25(1-2): 146-155. PMid: 17622998 http://dx.doi.org/10.5172/conu.2007.2 5.1-2.14

[23] Chang E, Hancock K. Role stress and role ambiguity in new nursing graduates in Australia. Nursing and Health Sciences. 2003; 5: 155-163. PMid:12709171

[24] Institute of Health and Welfare, Nursing and Midwifery Labour Force. Canberra: Australian Institute of Health and Welfare. 2010.

[25] Gui, L., K.L. Barriball, A.E. While. Job satisfaction of nurse teachers: A literature review. Part 1: Measurement, levels and components. Nurse Education Today. 2009; 29: 469-476. PMid:19111372 http://dx.doi.org/doi:10.1016/j.nedt.2008.11.002

[26] Conway J, McMillan M. Being in nursing: Dealing with contemporary practice. Contemporary Nurse. 2007; 24: 159-161. http: //dx.doi.org/10.5172/conu.2007.24.2.159

[27] Sekol MA, Kim SC, Job satisfaction, burnout, and stress among pediatric nurses in various specialty units at an acute care hospital. Journal of Nursing Education and Practice. 2014; 4(12) 115-123. http://dx.doi.org/0.5430/jnep.v4n12p115

[28] Ozden D, Karagozoglu S, Yildirim G. Intensive care nurses' perception of futility: job satisfaction and burnout dimensions. Nursing
Ethics. 2012; 20(4): 436-447. PMid:23411368 http://dx.doi.o $\mathrm{rg} / 10.1177 / 0969733012466002$

[29] Toh SG, Ang E, Devi MK. Systematic review on the relationship between the nursing shortage and job satisfaction, stress and burnout levels among nurses in oncology/haematology settings. International Journal of Evidence-based Healthcare. 2012; 10(2): 126141. PMid:22672602 http://dx.doi.org/10.1111/j.1744-1 609. 2012.00271.x

[30] Andrew N, Ferguson D, Wilkie G, Corcoran T, Simpson L. Developing professional identity in nursing academics: The role of communities of practice. Nurse Education Today. 2009; 29: 607-611. PMid:19250718 http://dx.doi.org10.1016/j.nedt .2009.01.012/

[31] Lloyd Jones M. Role development and effective practice in specialist and advance practice roles in acute hospital settings. Journal of Advanced Nursing. 2005; 49(2): 191-209. PMid:15641952

[32] Australian Nursing and Midwifery Council, National competency standards for the registered nurse. Dickson, Australian Capitol Territory: Australian Nursingand Midwifery Council. 2006. Available from: http://www.nursingmidwiferyboard.gov . $\mathrm{au} /$ Codes-Guidelines-Statements/Codes-Guidelines . as px\#competencystandards

[33] Lowe, G., et al. Time to clarify-the value of advanced practice nursing roles in health care. Journal of Advanced Nursing. 2012; 68(3): 677-685. PMid: 21790738 http://dx.doi.org/10.1111 /j.1365-2648.2011.05790.x

[34] Gui L, Barriball, KL, While, AE. Job satisfaction of nurse teachers: A literature review. Part II: Effects and related factors. Nurse Education Today. 2009; 29(5): 477-487. PMid:19118928 http: //dx.doi.org/10.1016/j.nedt.2008.11.003

[35] Sayers JM, DiGiacomo M. The nurse educator role in Australian Hospitals: implications for health policy. Collegian. 2010; 17(2): 77-84. Available from: http://www.journals.elsevier.com/ collegian/

[36] Nursing and Midwifery Board of Australia, Nursing and Midwifery Continuing Professional Development Registration Standard 2010, Australian Health Practitioner Regulation Agency: Canberra. Available from: http://www.nursingmidwiferyboard.gov.au/R egistration-Standards.aspx/ 